\title{
Using 'stories' in Nepalese medical schools
}

\author{
Pathiyil Ravi Shankar ${ }^{1}$
}

\author{
Editor \\ JMCJMS
}

Stories have been central to medicine during most of its long history but the meteoric rise and success of scientific biomedicine during the twentieth century eclipsed the presence of narratives in medicine [1].Stories and anecdotes became a derisive term and the patient's story shrank in the charts. Kathryn Montgomery, who has published books on Doctor's stories mentions that medicine is a rational interpretive activity with the patient as its text and seeks to understand his/her malady considering current evidence. There are close parallels between literary study and the patient encounter in clinical medicine. Both these processes according to Montgomery are based on narratives, the exchange of stories, attentive listening, and interpretation, and creating meaning.

The power of stories: Recently in developed nations narrative medicine has become increasingly common. Rita Charon, a physician, and literary scholar has championed the narrative medicine movement [2]. Narrative knowledge and the logico-scientific knowledge are both necessary according to her to produce physicians who practice with empathy, reflection, professionalism, and trustworthiness. Stories remain central to clinical medicine and doctors know, learn, and remember from patients using stories. Medical student stories can reflect memorable moments in their learning journey and present opportunities to exercise empathy and compassion toward patients, cultivate moral awareness, address ambiguity and uncertainty, and engage in self-care. Storytelling helps medical students and doctors to look at patients as whole individuals, to understand their perspectives, and to advocate for their health and wellbeing.

The 55-word story:Time is short in medical practice and the 55-word story can be an essential addition to the toolkit of a physician. This short piece of writing is an important tool for reflection on challenging topics [3]. The process of writing in 55 words forces students to concentrate on the essentialsof the situation and on the lessons learned.

Narrative medicine:The term narrative medicine (NM) was first used by Charon in 2000 as a model for effective practice in the humanities [4]. Research shows that students who participated in NM programs had better communication skills, ability to collaborate, increased respect for diversity, and listening skills[5]. Perspective-taking is an important skill supported by NM and literature and entails a person being able to think and feel from the mind/perspective of a specific individual other than the self[6]. NM increased capacity for reflection and empathy 
among medical interns in Iran and promoted professionalism [7].

Cultural humility and narrative competence:Cultural humility has been described as a stance oriented towards others and is associated with a desire for understanding, curiosity, and acceptance and remaining free from arrogance and egotism [8]. Storytelling has been used among nursing students to explain the concept of cultural humility and better prepare them for an international, intercultural experience [9]. Narrative competence is the ability to acknowledge, absorb, interpret, and act on other's stories [10]. A brief NM experience with a third-year internal medicine clerkship in a United States medical school improved narrative competence among the students [11]. Personal stories have been used to illustrate the core concepts of patient and family-centred care and to contribute to developing a health workforce with the ability to partner effectively, respectfully, empathically, and authentically with patients and their families [12].

Patient stories:NM improved empathy and clinical skills in Taiwan [13] and the United States (US) [14]. At Aga Khan University, Pakistan a NMworkshop organized in 2016 was attended by medical students, residents, physicians and non-medical professionals and served as an introduction to the subject [15]. At McMaster University in Canada, patient stories were used to teach medical students about the lived experiences of individuals with intellectual/developmental disabilities and to promote patient-centred communication [16]. At a college of osteopathic medicine in the US,patient perspective sessions during which actual patients share their medical stories and experiences with large groups of first and second-year students enhanced their empathy toward the patient experience and made the material addressed during the session easier to remember [17]. At a Taiwanese University NM was used to increase inter-professional collaboration and to provide medical and health science students an opportunity to listen to patients' stories and interact with each other [18]. The results were positive, and the authors mention that NM is worth recommending for interprofessional collaboration.

At a medical university in Malaysia, third-year undergraduate dental students were facilitated to discuss stories, engage in activities involving perspective-taking, and maintain a portfolio during the 'Stories and Perspectives' selective [19]. The authors concluded that reading stories and engaging in perspective-taking activities helps prepare health professionals for care giving encounters. In Nigeria, stories and anecdotes improved the quality of the daily obstetrics and gynaecology teaching and the emotions generated deepened the understanding of the material covered [20]. This was true for different levels of learners.

Medical comics: Medical comics were used to explore challenging situations within medical settings including the different perspectives of patients, caregivers, and medical staff [21]. Comics and pictures enable exchange beyond language and reading skills and play an important role in communicating with patients. Students critically read and discussed medically themed comics and created their own comic depicting a formative experience from medical school [22]. Students believe that engaging with and creating a comic can significantly improve many of the skills which have been mentioned previously. 
Childbirth and medical error:'The art of being born' started with a group of volunteers in 2008 who used art therapy (songs, poems, stories, crafts and cinema) to increase awareness of poor rural women about gestation, childbirth, and care of their babies [23]. The project was adapted for use in Mali and has been used in West Africa and in different parts of Brazil as a teaching strategy for different groups of health science students and contributed to the development of attitudes, health education skills and interprofessional collaboration. Patient safety is a critical issue in medicine and medical students could benefit by listening to stories of error narrated by clinicians [24]. Animated stories were effective in presenting these issues to a larger audience. In Saudi Arabia, a unique narrative novel story-based, peer-led surgical safety teaching session effectively engaged students in the cause of patient safety [25]. There are three things that can be done with stories according to Blackie and Wear [26]. These are close reading, modelling ethical and moral inquiry, and drawing out their illustrations. Close reading makes the two other things possible. The process shares similarities with the diagnostic process including paying attention to details, gathering and evaluating evidence, and weighing competing interpretations.

Nepal and storytelling:Storytelling was used in a school in Surkhetamong $11^{\text {th }}$ grade students to improve students' speaking proficiency [27]. Stories have been used to provide a voice to women, and to the oppressed and to address various social issues. In a medical college in Nepal literature excerpts were used during a medical humanities module [28]. Among the advantages mentioned by the participants were the stories will prepare them for future practice, helped them to understand patients' feelings, introduced them to difficulties faced by doctors, and was a better and more interesting way of learning.

The ubiquitous presence of mobile phones even in rural Nepal makes it easier to record patient stories. Students can obtain a perspective on the different ethnicities and groups inhabiting different regions. Stories could be an important communication tool during the community diagnosis postings. As done elsewhere stories can be used to educate about medical error, to improve student resilience and for improved interprofessional collaboration. Stories can be used to understand the perspective of the marginalized and of the physically and intellectually challenged. Stories can be an important medium for public health education. Many other uses for stories can also be conceptualized. Stories have an important role to play in medical education in Nepal and medical schools should begin to explore the possibility of introducing stories in the curriculum.

\section{REFERENCES}

1. Childress MD. From Doctors' Stories to Doctors' Stories, and Back Again. AMA J Ethics. 2017;19:272-80.

2. Charon R. The narrative road to empathy. In: Spiro H, McCrea Curnen MG, Peschel E, St. James D. Empathy and the Practice of Medicine: Beyond Pills and the Scalpel. New Haven, CT: Yale University Press; 1993:147-59.

3. Fogarty CT: Fifty-five word stories: "small jewels" for personal reflection and teaching. Fam Med 2010;42:400-2.

4. Charon R, Hermann N, Devlin MJ. Close reading and creative writing in clinical education: teaching attention, representation, and affiliation. Acad Med 2016;91:345-50.

5. Sands SA, Stanley P, Charon R. Pediatric narrative oncology: interprofessional training to promote empathy, build teams, and prevent burnout. J Support Oncol 2008;6:307-12. 
6. Decety J, Cowell JM. Friends or foes: is empathy necessary for moral behavior? PerspectPsychol Sci 2014;9:525-37.

7. Daryazadeh S, Adibi P, Yamani N, Mollabashi R. Impact of narrative medicine program on improving reflective capacity and empathy of medical students in Iran. J Educ Eval Health Prof 2020;17:3.

8. Owen J, Tao KW, Drinane JM, Hook J, Davis DE, Kune NF. Client perceptions of therapists' multicultural orientation: Cultural (missed) opportunities and cultural humility. Professional Psychology: Research and Practice 2016;47:30-7.

9. Matthew S, Hockett E, Samek L. Learning Cultural Humility Through Stories and Global Service-Learning. J Christ Nurs2018;35:33-7

10. Charon R. The patient-physician relationship. Narrative medicine: a model for empathy, reflection, profession, and trust. JAMA 2001;286:1897-902.

11. Chretien KC, Swenson R, Yoon B, Julian R, Keenan J, Croffoot J, Kheirbek R. Tell Me Your Story: A Pilot Narrative Medicine Curriculum During the Medicine Clerkship. J Gen Intern Med 2015;30:1025-8.

12. Johnson BH. Promoting Patient- and FamilyCentered Care Through Personal Stories. Acad Med 2016;91:297-300

13. Chen P-J, Huang C-D, Yeh S-J. Impact of a narrative medicine programme on healthcare providers' empathy scores over time. BMC Med Educ2017;17:108.

14. Arntfield SL, Slesar K, Dickson J, Charon R. Narrative medicine as a means of training medical students toward residency competencies. Patient EducCouns2013;91:280-6.

15. Baqir H, Nayani K, Mian A, Mian AI. Initiating Narrative Medicine at a Medical College in Pakistan: Achievements, Challenges, and Opportunities. Perm J 2019;24:18.194.

16. Coret A, Boyd K, Hobbs K, Zazulak J, McConnell M. Patient Narratives as a Teaching Tool: A Pilot Study of First-Year Medical Students and Patient Educators Affected by Intellectual/Developmental Disabilities. Teach Learn Med 2018;30:317-27.

17. Hendriksz T. Using Patient Perspective Sessions to Increase Empathy and Recall in Preclinical Medical Students. J Am Osteopath Assoc 2016;116:662-6.
18. Liao HC, Wang YH. Storytelling in Medical Education: Narrative Medicine as a Resource for Interdisciplinary Collaboration. Int J Environ Res Public Health. 2020;17:1135.

19. D Mani S, Chen NLP, Menon V, Babar MG. Stories and perspective taking: Augmenting dental students' understanding of patient care. Med Teach 2019;23:1-7.

20. Ogueh 0. In What Ways Might Stories and Anecdotes Impact upon the Quality of Small Group Teaching in Obstetrics and Gynecology? Niger Med J 2019;60:80-6

21. Masel EK, Adamidis F, Kitta A, et al. Using medical comics to explore challenging everyday topics in medicine: lessons learned from teaching medical humanities. Annals of Palliative Medicine 2020;9:1841-6

22. Green MJ. Comics and medicine: peering into the process of professional identity formation. Acad Med 2015;90:774-9.

23. Damasio Santos CA, Lisboa LL, Cassiano AN, de Lima AS, Oliveira Freitas-Junior RA. Aarte de nascer (The art of being born). Educ Health (Abingdon) 2019;32:150-3.

24. Cooper K, Hatfield E, Yeomans J. Animated stories of medical error as a means of teaching undergraduates patient safety: an evaluation study. Perspect Med Educ2019;8:118-22.

25. Baqal OJ, Soheib M, Saadallah AA. Peer-Led Surgical Safety Learning Among Medical Students Using a Novel Story-Based Approach. Cureus 2020;12:e10242.

26. Blackie M, Wear D. Three Things to Do With Stories: Using Literature in Medical, Health Professions, and Interprofessional Education. Acad Med 2015;90:1309-13.

27. Sharma D. Action Research on Improving Students' Speaking Proficiency in Using Cooperative Storytelling Strategy. Journal of NELTA Surkhet 2018;5:97-105.

28. Shankar PR, Singh KK, Dhakal A, Shakya A, Piryani RM. Student feedback about the use of literature excerpts in Sparshanam, a Medical Humanities module. F1000Res 2012;1:49.

\section{Correspondence to:}

P Ravi Shankar

MD, FAIMER Fellow

IMU Centre for Education

International Medical University

Kuala Lumpur, Malaysia

E-mail: ravi.dr.shankar@gmail.com 